\title{
SUPPORTING FACULTY TO FACE CHALLENGES IN DESIGN AND DELIVERY OF QUALITY COURSES IN VIRTUAL LEARNING ENVIRONMENTS
}

\author{
Dr. Francis KIBARU \\ Department of Information and Communication Technology \\ Commission for University Education \\ Nairobi, Kenya
}

\begin{abstract}
Existing guidelines, standards, and frameworks for addressing quality of online courses often highlight the importance of setting up effective systems to support faculty in overcoming the emerging challenges they face in design and delivery of these courses. However, not much information is available in literature on the means of tackling these difficulties, which are ever evolving in line with the dynamic nature of learning technologies and mode of teaching and learning in virtual environments. This qualitative study sought to identify these challenges and emerging solutions. Data was collected using interviews with academic administrators and faculty experienced in design and delivery of online courses and programs. As a result, several themes emerged, among them the need for an academic institution to dynamically adapt its mission and culture to the evolving nature of online teaching and learning. Other emergent challenges and suggested solutions are discussed.
\end{abstract}

Keywords: Faculty support, online learning, distance education, e-learning.

\section{INTRODUCTION}

As online education continues to grow in higher education institutions (HEIs) (Allen \& Seaman, 2017; Jung, Wong, Chen, Baigaltugs, \& Belawati, 2011), faculty in HEIs are increasingly under pressure to teach online (Kim \& Bonk, 2006; Hunt, Davis, Richardson, Hammock, Akins \& Russ, 2014). This is despite the fact that online education is a fairly recent mode of instruction delivery, and majority of HEI faculty have little or no experience either as students in online education or as instructors of online courses.

Faculty play crucial roles in planning, design and delivery of online courses. However, anecdotal evidence indicates that HEIs often require faculty to offer online courses without providing them with the skills and knowledge necessary to be successful online instructors. Weaver, Robbie \& Borland (2008) noted that with increased offering of online courses, faculty are often required to utilize pedagogical and technological skills that they may not necessarily possess. According to Berge (1995), online instructors perform pedagogical, social, managerial, and technical roles through which they are able to create learning environments where students can actively learn using higher-order thinking skills. Liu, Bonk, Magjuka, Lee, and Su (2005) discussed other critical roles that faculty play in design and delivery of online courses. Lack of skills and knowledge necessary to play these roles might pose a challenge for online course quality since many faculty may "teach as they were taught, in traditional classrooms with teacher-centered strategies dominated by lecture and discussion" (Taylor \& McQuiggan, 2008, p. 30), and, therefore, online learning environments may tend to be imitations of traditional face to face courses (Twigg, 2001). Furthermore, since online courses differ in character from traditional courses (Jung, 2010; Jung, 2008; Stella \& Gnanam, 2004), faculty who offer online courses might face challenges that arise from the virtual nature of the environment in which they deliver instruction, 
unique from those they could experience while teaching similar on-campus courses. It therefore, becomes increasingly important to offer faculty the support they require, in order to deliver quality online courses and programs (Baran \& Correia, 2014).

Extant standards and frameworks for evaluating online courses often include faculty support as a key measure of course quality. In a review of thirteen paradigms for evaluating online learning, Shelton (2011) found that faculty support was a recurring theme for indicating quality. Daniel and Uvalic-Trumbic (2013) reviewed standards for quality online learning and found that faculty support is identified as critical for successful online teaching. Similarly, Martin, Polly, Jokiaho and May (2017) in their review of twelve standards for online learning used in different countries, also found that faculty support was considered as a key indicator of quality online learning in a majority of the standards. Recent studies such as (Baran \& Correia, 2014) and Martin and Parker (2014) suggested that faculty support plays a key role in ensuring high standards of online teaching and learning. Other studies have indicated that administrators of HEIs acknowledge the necessity of providing support to faculty offering online courses (Sellani \& Harrington, 2002; Garza, 2009; Orr, Williams \& Pennington, 2009).

Even though HEIs offering online education might have some form of faculty support mechanisms, not much information is available on how such systems adapt to the emerging fundamental challenges faced by faculty in design and delivery of online courses. Due to the dynamic nature of online courses (Garza-Mitchell, 2010; Shelton, 2011), it is plausible to assume that challenges that faculty face in designing and delivering online courses are also evolving. For example, there are increasingly newer and improving technologies that could be used to engage learners in meaningful learning activities in online learning environments (Dabbagh, \& Bannan-Ritland, 2005; Ko \& Rossen, 2010). A recent phenomenon such as use of learning analytics has been suggested as a good way to improve the design and delivery of instruction to make it more meaningful (Martin \& Ndoye, 2016). Studies by Clark, Tanner-Smith \& Killingsworth (2016) and Merchant et al (2014) have indicated that emerging technologies such as simulations and virtual worlds could be used effectively to enhance the levels of learner motivation and engagement. However, for such emerging technologies to be brought to the attention of faculty and to be meaningfully utilized to in delivery of quality online instruction, faculty should be offered the necessary technological and pedagogical support. Support is especially critical for faculty with little or no experience with online teaching (Hunt, Davis, Richardson, Hammock, Akins \& Russ, 2014). Previous studies have highlighted the fact that often, challenges faced by faculty in use of fast evolving learning technologies is a key hindrance to quality online teaching and learning (Bolliger \& Wasilik, 2009; Lieblein, 2000; Hunt, Davis, Richardson, Hammock, Akins \& Russ, 2014).

Friendman (2017) and Smith (2014) have indicated that online education is likely to make even bigger changes in the foreseeable future, which might impact the way online courses are taught and likely begging for enhanced faculty support. Friendman (2017) identified the following as the likely trends that stakeholders in online education need to watch: 1) greater emphasis on nontraditional credentials; 2) Increased use of big data to measure student performance; 3) Greater incorporation of artificial intelligence into classes; 4) Growth of nonprofit online programs; and 5) Online degrees in surprising and specialized disciplines. Smith (2014) identified the following trends in online learning: 1) big data; 2) gamification; 3) personalization; 4) mobile learning; 5) focus on return on investment; 6) Application Programming Interfaces (APIs) ; 7) automation; 8) augmented learning; 9) corporate MOOCs; and 10) rise of cloud Learning Management Systems (LMS). Dynamism in online learning suggests that the nature of challenges that faculty face in design and delivery of online courses change with time.

If online course quality is to be achieved and maintained, faculty need to keep themselves updated with the dynamic nature of online learning and emerging learning technologies, whilst efforts are made to address, in a timely fashion, challenges that they encounter in doing so. 
It is unclear whether or not HEIs continually engage faculty to identify the difficulties they could be facing as they design and deliver online courses. . One might arguably contend that proactively identifying and providing the necessary support or remedies to the challenges that faculty face in this respect, is crucial, not only in maintaining the relevance of faculty support systems, but in possibly improving the quality of online courses. Few studies have examined the challenges that faculty face in design and delivery of online courses, as they make efforts to keep pace with the changing nature of online education.

The purpose of this study was to identify the main challenges that faculty perceived that they faced in their efforts to design and deliver quality online courses, and to highlight some proposed solutions. Specifically, the study sought to answer the following research questions:

$>$ What challenges do faculty perceive that they face in their efforts to design and deliver quality online courses in a rapidly changing online learning environment?

$>$ What recommendations could be given to administrators of HEIs and online program administrators to confront the challenges faced by faculty in design and delivery of quality online courses?

\section{RESEARCH METHOD}

According to Creswell (2007), naturalistic modes of inquiry allow the researcher to establish details of an issue by talking directly with those who can provide required information to better understand the context in which the issue under investigation renders itself, and how participants address it. We considered in-depth, one-on-one interviews with participants to be most appropriate in allowing us to acquire a deep understanding of the challenges that participants encounter in the process of designing and delivering purely online courses. In the study context from which participants were drawn, online instructors mainly design and deliver their own courses even though instructional system designers are freely available to offer support. Using qualitative methods also allowed us to be open to themes emerging from data.

Participants in this study were faculty and academic administrators. We considered it fitting to include academic administrators because they were directly involved in providing solutions to issues related to online instruction. Faculty participants were drawn from the College of Education of one campus of a multi-campus research intensive university in Midwestern U.S. The university is accredited by the North Central Association of Colleges and Schools - the Higher Learning Commission (NCA - HLC), which is recognized by the Council for Higher Education Accreditation (CHEA) and the U.S. Department of Education. This college was selected as the study context because it had offered more online courses than most other colleges at the institution, and over a longer period. It was among the colleges that started offering online courses and programs from the time they were introduced at the institution over thirty years earlier. The College was the first in the university to offer a fully online master's program, and offered among the highest number of continuing and distance programs in the university.

We invited the study participants through letters approved by the university's Institutional Review Board (IRB). A total of five academic administrators (who will henceforth be identified as A1, A2, A3, A4, and A5), five faculty members (identified in this study as F1, F2, F3, F4, and F5) participated in the study. Only faculty who had taught fully online courses for at least two academic years were selected to participate.

We invited one of the most senior academic administrators, who by virtue of his position, was expected to have 'rich information' on the topic of inquiry, to participate in the study. Subsequently, in order to access other academic administrators who had relevant information, we used the snowball sampling strategy. According to Miles and Huberman 
(1994), snowball sampling "identifies cases of interest from people who know people who know what cases are information rich" (p.28). In this case, the senior academic administrator proposed all the other four administrators who participated in the study.

\section{Participant Profiles}

One male and four female academic administrators participated in this study. One was aged between forty and forty nine years, three were aged between fifty and fifty nine, and one declined to reveal her age range. All had doctorate degrees. Four had over ten years of academic administrative and leadership experience while one had between five and ten years. Also, four had over ten years of teaching experience in higher education while one had between five and ten years. Two had over ten years of teaching experience at the institution where this study was conducted, two had less than five years, while one had between five and ten years of teaching at the same institution. All administrator participants indicated that they had taught less than five fully online courses in higher education and three had not taken any online courses at all, while two had taken no more than five online courses, while they were students. Three considered themselves to have intermediate IT skills while two considered themselves to have expert IT skills. However, all administrator participants indicated that they had over five years of experience in handling faculty matters related to online courses and programs.

Four female and one male members of faculty at the College of Education participated in the study. All were doctorate degree holders, with one of them aged between forty and forty nine years, three aged between fifty and fifty nine, and one aged over sixty. Four were tenured and one was not-tenured. Four had over ten years of teaching experience in higher education and one had between five years and ten years. Three had over ten years teaching experience at the institution where this study was conducted while two had between five and ten years of teaching in the same institution. Two had taught over five while three had taught less than five different fully online courses. None of them ever took a fully online course as students, and none got any technical or pedagogical training related to online teaching. Three considered themselves to have intermediate level of IT skills while two considered themselves as experts in IT matters. Between them, two of the faculty participants had won several teaching awards or recognitions, including Excellence in Teaching with Technology award, Graduate Instructor of the Year award, and Graduate Mentor of the Year award. Also, these same two faculty had been nominated in a number of other past years for the Excellence in Teaching with Technology award.

\section{Data Collection}

One-on-one, in-depth interview with each participant and a demographic questionnaire formed the primary mode of data collection. Each administrator participant was asked to articulate in detail what they perceived to be the challenges that faculty face in design and delivery of online courses. Faculty participants were asked the same question, but requested to draw from their own experiences. All participants were then invited to suggest solutions to the challenges identified and strategies of further enhancing the quality of online courses at the university.

In order to ensure consistency, one researcher interviewed all participants. Before commencement of the interviews, participants were asked to show acceptance to participate in the study by signing a consent form approved by the IRB. Participants did not have access to interview questions prior to the interview. Each interview was conducted at a time and place convenient to the participant and lasted about one hour. Interviews were audio recorded using two recording devices as a data backup strategy. The interviewer also took hand-written notes during the interviews for the same reason. Each interview was then transcribed. In order to protect participant identity, each participant was referred to using a pseudonym in the interview transcriptions and the hand-written notes. The interview recordings were stored in a secured computer and in secured storage locations in the researcher's home office. 
The interview protocol was piloted by first requesting an experienced online education researcher to review the interview protocol and the demographic questionnaire for meanings and clarity. Next, three potential participants (one academic administrator and two faculty) were recruited purely based on convenience sampling, to participate in the pilot study. Doing this enabled the researcher to check for and ensure general understandability of the interview protocol and the demographic questionnaire. Only faculty who had taught fully online courses for at least two academic years participated in the pilot study.

\section{Data Analysis}

Data were examined at the individual participant level in order to identify patterns and major themes. The researcher and an experienced online education researcher first participated independently in data analysis. In order to identify themes, each of the two researchers went through all the ten data transcriptions and sorted out the content into piles of related topics using MAXQDA software. The two then compared the common challenges emerging from data and agreed to list as 'major' those that were mentioned and discussed by four or more participants. These major emerging challenges were then grouped into three themes discussed below.

In order to enhance the trustworthiness of the qualitative inquiry method used in this study, peer-review, member checking and detailed description of findings were employed (Lincoln and Guba, 1985). As explained earlier, the interview protocol and demographic questionnaire were peer reviewed and the study piloted. The researcher also sought the views of two participants - one faculty and one administrator - on the credibility of the findings and interpretations of the results. Further, participant quotes were used extensively to support and explain emergent themes. In this study, the researcher made efforts to remain as objective as possible throughout the research process and to let the data "speak for itself" without trying to fit it within his knowledge and experiences. Participant quotations were included in order to explain the findings.

\section{RESULTS}

In this study, we sought to identify the challenges that faculty face in their efforts to design and deliver quality online courses, and suggested solutions for overcoming these challenges. We compiled and analyzed responses for common emergent themes. The main challenges that emerged could be broadly grouped into three themes: 1) Proximity to learners, 2) teaching load, and 3) faculty support. The following table shows each of these themes and the challenges grouped under it.

Table 1. Perceived Faculty Challenges in Design and Delivery of Quality Online Courses

\begin{tabular}{ll}
\hline Themes & Attributes (Faculty challenges) \\
\cline { 2 - 2 } Proximity to learners & $\begin{array}{l}\text { - Limited opportunities for understanding } \\
\text { learners } \\
\text { - Difficulties in observing and assessing practical }\end{array}$ \\
\hline Teaching load & $\begin{array}{l}\text { Teaching online is time-intensive } \\
\text { - Perceived negative impact of large online } \\
\text { classes }\end{array}$ \\
\hline Faculty support & - Ligh level of support in course design \\
& - Challenges in keeping updated with technology \\
& - Limited opportunities for information sharing \\
& - Inadequate funding and processes of \\
& technology acquisition \\
\hline
\end{tabular}




\section{Proximity to Learners}

Faculty participants expressed the challenges brought about by distance between them and their students. In particular, they discussed the difficulties that virtual environments may present in understanding learners and their learning needs, and in observing and assessing the practical application of knowledge gained in an online course.

\section{Limited Opportunities for Understanding Learners}

Faculty expressed the view that in purely online courses, the distance between the instructor and learners limits the opportunities for forming connections and building relationships that facilitate effective interactions that are necessary for deeper understanding of the learners and their learning needs. According to some faculty, lack of face-to-face contact in online learning environments (OLEs) leads to faculty-learner relationships that are somewhat "abstract", making it difficult to know when students do not understand concepts. Consequently, it is often challenging for them to understand learners and their learning needs in order to provide timely interventions to poor performers. This is illustrated in the following sample quotations:

....it is very difficult to know your students without opportunities for personalized experiences. I am not saying just face-to-face, but you know your students only in a relationship.....they may provide some blogs about themselves, they may provide photos, but other than that it is just turning in assignments, or participating in discussions. These are all kind of abstract... you do not have the close knowledge of knowing the student as a person.... [F1]

.... one challenge is that you have to trust students to know when they don't understand. In a face to face class, you can see the puzzled looks on their faces. And so I think for students who are struggling, it's harder to remediate; it's harder to do that when you're not in the same room [F4].

One of the faculty participants (F3) introduced a compounding angle to this argument, claiming that even when students are clear on the areas they don't understand or issues they need clarification about, some of them have misgivings about posting their questions online. She argued that some students find it difficult to post on a learning management system (LMS) or other online applications, questions that they would easily ask the course instructor or another student in a face-to-face setting. She said:

Because the course is online, people are going to be a more reluctant to seek help after having a hard time understanding the core material. Because there is no that person that they met in class to whom they can say: "hey, can you help me?".......it is much more embarrassing I think for some to reach out. Having to write on the course system, "hey, I don't understand this". Because then it is permanent. If I just say something to you in the hall way: "hi, XYZ (name) are you too busy?" There is something I do not know.... it is gone. There is no written record of it. You care enough not to tell somebody else about it, but if I write it, it is permanent in digital space. $I$ think that is what makes a lot of students reluctant to write on message boards. Some people really like the message boards because they know what to write. Other people are like, "oh men, what if I say something and it is stupid? It remains there forever you know...." [F3]

Like F4, F2 explained the importance of visual cues saying that when he first started teaching online, he felt disconnected from students because he did not get immediate feedback in form of facial expressions, which he got from students in on-campus courses. He stated: 
....at the beginning $I$ was very uncomfortable not having immediate feedback. Nonverbal or verbal feedback from the students.... with my training in psychology you use visual cues all the time. So to not have that in your instruction was certainly ... it felt disconnected from the students. [F2]

\section{Difficulties in Observing and Assessing Practical Application of Knowledge}

A faculty participant, who said she taught both a purely online section and an on-campus section of a course in a program that trains special education teachers, explained the challenges she faced in assessing performance of practical skills. She indicated that she found it difficult to assess how well her online students had mastered critical skills necessary in handling students with special needs. She indicated that she was unable to observe how her online students practically applied the knowledge they have gained. She said:

.... one of the challenges isn't necessarily with the course itself. But, with the students I have on campus, I can see them practice with children with special needs. So I can watch them perform, and I can know: Oh, they do not understand this because they're not doing it with a sixteen month old. So I need to revisit that. I don't get to do that in the online program..... because the content, I mean, it's a practice content. How is it being applied in the field? Which is what we really care about, and I don't have access to that for students who are around the world [online students].....[F5]

\section{Teaching Load}

A common theme among faculty participants was that teaching online is time intensive and that the situation gets worse when the number of students is relatively high.

\section{Teaching Online is Time-Intensive}

While not undermining the amount of planning and preparation required for effective teaching in any format, majority of the participants were of the opinion that the process of designing and delivering a quality online course requires diligence and good planning in more processes than are normally necessary for a similar face-to-face course. For example, participants frequently brought up the issue of the amount of time taken up communicating to learners. Online learners often have more channels to interact with their instructor such as email, instant messaging, chats, blogs, discussion boards, and online conference meetings. While faculty appreciated this as part of their work, some of them admitted that sometimes the volume of communication requiring their attention often felt like it was 'invading their life'. F2 explained it as follows:

...there is this issue, how do you put boundaries on that course so that it's not invading your life all the time? When it's an online course you can do it whenever ......., you can be involved in the course whenever you want. If I have a course from nine to ten on Tuesdays that I teach face to face, that's when I teach. I'm done. But, you know, it could be ten at night or six in the morning and I could get online and be involved in the course. So how do I put boundaries around it?

F2 also remarked that faculty often face dilemma in judging the levels of interaction with students "that allows the student to see that they're good value as well. That they're not just being taught by the other students."

A majority of faculty interviewed indicated that they mainly assessed their online students through multiple course projects and discussions. They were of the view that grading those projects, providing personalized feedback, participating in discussions, as well as 
responding to communication from learners was often overwhelming to them, since it was mainly text based. This is exemplified by the following comment by F1:

In project based courses like the ones I teach, you generally have multiple projects that must be turned in and responded to with feedback. That quantity, call it grading, call it feedback, whatever, that quantity is enormous in online courses because all your evaluations is coming through either products that are submitted or participation and discussion. It is much more time consuming than just sitting and watching a group process, in face-to-face class. You have to monitor and grade participation and discussion. You have to go back through artifacts and review, provide feedback, understand, and respond to students' questions about what you said. Very, very time consuming...

F3 also felt that online teaching is a lot more work and requires faculty to spare extra time to organize their courses, than in traditional teaching, if they are to be successful as online instructors:

Online teaching is a lot more work. It's different and more work than an on campus course. Because it's constant. You have to be very organized as an instructor, because you get emails all day long, every day. It's not like an on-campus course, where you see your students once a week. You hear from them all the time [in an online course]. For really minor things. .....and so, you can either be active twenty four hours every day, or learn how to pace yourself. It's a lot of work [F3].

\section{Perceived Negative Impact of Large Online Classes}

Faculty expressed the view that the number of students in an online course is negatively related to elements such as the frequency and quality of interactions and feedback; and, the ability to form relationships between the instructor and students, and, between students themselves. Respondents also indicated that an increase in class size increases the instructors teaching load more in online courses, than the same increase of class size in a similar on-campus course. While participants generally agreed that it is more difficult to ensure quality in large classes regardless of whether they were online or not, they indicated that large online classes present challenges that might be there only in lesser degree in a similar large on-campus course. Large online classes also make the challenge of creating personalized experiences for learners much worse. Here are some comments from faculty F3 and F1 relating to the perceived impact of class size on the quality of an online course:

...the challenge for me is with the university. They keep upping the cap. You know, increasing the number of students that can be in a course. If you want a quality course, from teaching, you shouldn't have more than 15 students in a course [in her discipline] .... and, right now, I know people with, you know, thirty students in an online course, and it's horrible. That's when you start to get difficulties keeping pace on discussion boards, and the teacher doesn't check in, and students don't get feedback on their work. That is not a quality course. And part of that is, it's hard to keep track of more than thirty students in an online course [F3].

.... a real concern $I$ have is the size of online courses. The number of students that they would like to load into that.... if you were teaching a face-to-face graduate course on campus, you might have 15 students and you can easily know 15 students, their backgrounds, their interests, and the kinds of challenges that they face. So, I would like online courses to have a minimum of 18 [students]. But they are usually 30 to 35 students with one instructor... [F1] 
Participants were generally of the view that a large online class complicates implementation of instructional methods such as discussions and group work, which, depending on the nature of the course and desired learning outcomes, they considered to be some of the important ways of engaging online students.

\section{Faculty support}

Despite the fact that the university had a faculty support mechanism that administrators and some of the faculty participants described as good, faculty still felt that there was room for improvement. In particular, they cited the need for improved technological, pedagogical, and administrative support in order to overcome issues arising from: course design, limitations of course management systems, acquisition and maintenance of newer innovative technologies for teaching and learning, and keeping updated with relevant technologies.

\section{High Level of Support Required in Online Course Design}

According to faculty participants, course design for OLEs requires more skills and more support than in traditional courses. Participants indicated that designing online courses requires a high level of skills in use of learning technologies, in addition to pedagogical skills and content knowledge. They, therefore, felt that faculty teaching online courses often require a lot of technical support in accessing and using technology, and in course design. One participant said:

I think designing online courses is more difficult because you are designing for the asynchronous environment. That would be another challenge.... The more times you teach and revise a course, the more that you work out some of those problems. I think technology support from your institution is also very important. How much assistance you get and using technology or are you just out there on your own, learning about new technologies, figuring out how to use and experimenting with them, getting them setup......technical support is also needed on a technology product that isn't really your product ..... In online courses, not only are you the instructor, but you are expected to be the technical expert too. So that is another area of challenge [F1].

Another faculty participant [F4] discussed the need for support from institutional academic leaders especially in getting release time to develop new online courses; "if you don't have a course release, and you are developing using a whole new technology, the time to really do it isn't there." F2 also reminisced on the difficulties he had as a beginner online instructor:

... when I started teaching online I had no training whatsoever about how to do it. And basically, it was 'this is what the other person did the last semester this was offered. Here's the book. Here's how they did it.' And so I take it and I go, 'Okay, I guess I'm going to do pretty much what they did.' I didn't know whether it was good. I didn't know whether it worked. I didn't know how to use the technology. I probably still don't know all the technology that could be incorporated into an online course. The benefits, such as, 'are there things that can save me time? Are there things that can get the material across to the students better?' [F2]

F2 believed that it would have been helpful if before he started teaching online, he had been introduced to aspects such as how design of online learning environments differs from that of traditional courses, as well as getting tips on how to effectively utilize technology for teaching and learning in online courses.

In discussing the challenges of designing for OLEs, F3 explained that since most online communication is text based, faculty need to take extra care to ensure that they convey the intended messages to avoid misunderstanding. This perspective was echoed by another 
participant [F5] while discussing issues that might affect the quality of an online course. She said:

Some students have complained of instructors who are kind of snarky about students' questions. You know, sometimes students will post on the discussion board if they were confused about an assignment, didn't agree with something in the assignment or something that the instructor said, and some professors are very willing and open to that feedback but some might just be very rude about it. It has happened multiple times. And some of that could just be perception because you are not there face to face, so it is possible that their tone was coming across as perhaps more sarcastic and rude than they intended, but it is very easy in online courses to not be able to get tone correctly. Someone could write something on the screen that to them is totally innocent, fine. And you read and you are like, what?! I mean, it is just very easy to take offence in things that are not necessary offensive, and some professors are very quick to put little smiley faces.... Having a period or an exclamation mark can make all the difference in how it comes across. $I$ just think that it can be very hard to get your meaning across [F5].

Participants felt that faculty need to have the skills that enable them to use precise and unambiguous language in virtual learning environments (VLEs).

\section{Limitations of Course Management Systems}

In the institution in which this study was conducted, Blackboard and Sakai were the commonly used Course Management Systems (CMS) for delivering online courses. However, some faculty participants were of the view that these two systems did not offer all the features they often needed in order to effectively meet their instructional objectives. Instead, they reported that they utilized a variety of other technologies and computer tools to augment the CMS supported by the institution. In particular, they were unhappy that these CMS did not adequately meet their expectations in supporting personalized experiences for students through synchronous audio and visual communication; and that they lacked a well-organized common area where learners could carry out a wide variety of learning activities and tasks, such as uploading artifacts that they have created, blogging, and creating sites where they could interact. That is, they lacked a common point where learners could use multimedia to interact. Participant F3 commented:

I don't like Blackboard. It's limited. That's why I go out and use other tools. Um, I think limitations are probably the biggest challenge. Okay, so one course I'm teaching now I created a website where I can put videos of them. They had to submit teaching videos, so I posted all of those videos for them. And then under the same website has individual blogs they write about-so they watch videos they posted and then they write, comment, to each other. I like individual websites for courses because it's very self-contained. Blackboard doesn't really have a place for a selfcontained website. So sometimes - even for this course - I didn't even use Blackboard, I only used the website. [F3]

Explaining why she uses other computer tools to augment the affordances of the CMS supported by the institution, F1 said:

...I think a quality course needs to look at various methods to provide that engagement and interactivity because as online technology continues to develop, there are more and more tools that can be used such as presentation on Tegrity, Prizo, Voicethread as a way to support more of a multi-media format in discussions... [F1] 
Challenges in Keeping Faculty Updated with Technology

Faculty participants indicated that they were aware of the ever increasing number of technologies that could potentially be used for teaching and learning, but expressed concern that they generally lacked the enormous amount of time required to adequately explore them. Some said that they found it difficult to keep up with technology upgrades and newer technologies, even those they knew were particularly useful for their courses. This is partly because learning technologies increase and change rapidly. Also, due to the time constraints, faculty said that they found it convenient to rely heavily on the technologies supported by the institution and those that they were already familiar with. In relation to this, $\mathbf{F} 1$ said:

... You [instructor] tend to only use what you know and there needs to be a better way of sharing new information and providing easy ways for faculty to become users of that...... I mean the online courses aren't going to continue to evolve and get better unless there are better mechanisms for bringing in that information [to faculty]. It can be better technology, newer technology; it can also be what have we learned, what is effective. How might you be able to use this to redesign your course?... [F1]

F2 believed that even though faculty might be aware of the affordances of various technologies that could be appropriated to improve online instruction, often, they not only lack the pedagogical skills necessary for effectively employing these technologies in their instructional strategies, but also do not have the technical knowhow and wherewithal to keep up with rapid technical changes to these technologies. Furthermore, he argued that in a research intensive HEI where there is more emphasis on research than teaching (like the one where this study was conducted), faculty might not be motivated to invest a lot of time on activities related to teaching such as technology innovations and keeping themselves updated with emerging or updated learning technologies. One administrator participant noted that supporting faculty in keeping updated with current innovative technologies for teaching and learning was a big challenge for the institution especially because of the wide diversity of faculty needs in the many academic disciplines that the university offered.

\section{Limited Opportunities for Information Sharing}

Participants indicated that faculty who teach purely online courses often lack the opportunities to exchange information related to professional growth with their colleagues and might experience feelings of isolation. One faculty (F3) expressed regret that her work as an online instructor made it difficult for her to meet and socialize with other faculty. Teaching online courses, she stated, allowed her to work away from campus and so she often missed face-to-face interactions with professional colleagues and opportunities for support from them. She referred to feelings of isolation and lack of contact with colleagues as a 'personal challenge'. She said:

This year, I taught $100 \%$ online.... and sometimes I will notice I'll get up at seven, go online, and all of a sudden it's ten in the night. But that's a personal challenge. It's just different [teaching online]. It's just different. You know, you can't walk down the hall and talk to a colleague. I don't see any colleagues. You know, it's hard to explain, it's just different. Yeah, it's a hard thing to explain...[F3]

\section{Inadequate Funding for Technology Acquisition}

Faculty participants reminisced inadequacy of support provided to them in acquiring and maintaining newer, innovative technologies for teaching and learning. They cited lack of funding to support acquisition of technologies as a challenge that hinders faculty from freely exploring and using innovative technologies for effective teaching and learning. F1 commented: 
...I think we have really been missing on technology support. Money to support technology that faculty want to experiment with. If I am teaching a course and $I$ want students to use a particular software program. First of all I need to able to learn that software program. Someone needs to provide it to me and then working out student rates or group rates. And then there is need for assistance in getting it to students, either through student cost programs or probably on a rare basis technology loaner program where college might buy....[F1]

Even though the university in which this study was conducted offers technical and pedagogical support to faculty in exploring and making use of learning technologies in their disciplines, faculty participants indicated that available funding could not cater for technology acquisition needs of each faculty member. However, they felt that better mechanisms should be put in place to prioritize faculty technology needs and to make it easier for faculty and students to access technologies that they may want to use to enhance teaching and learning.

\section{SUGGESTIONS FOR IMPROVING ONLINE COURSE QUALITY}

In discussing the challenges that faculty perceived they faced in their efforts to design and deliver quality online courses, participants also suggested solutions to these challenges, as means of improving the quality of online courses. Generally, faculty and administrator participants felt that there was still room for improvement on the initiatives that the university had undertaken to ensure quality of online courses and programs. Faculty participants in particular had more suggestions for improvement than administrators. Proposed solutions emphasized the need to adjust the institutional mission and culture, to further promote quality in online teaching and learning.

Table 2. Suggestions for Improvement of Online Courses

\begin{tabular}{ll}
\hline Theme & Attribute (Suggestions for improvement) \\
Institutional mission & - Promote excellence in teaching \\
\hline $\begin{array}{ll}\text { Quality improvement } \\
\text { culture }\end{array}$ & - Enhance faculty support \\
& - Optimize class size \\
& - Improve the process of acquisition and use of \\
& teaching and learning technologies \\
& - Make strategic use of data \\
& - Develop and nurture a culture of continual \\
& improvement \\
\hline
\end{tabular}

\section{Institutional Mission}

Faculty and administrator participants consistently emphasized the need to increase the stature of teaching at the university. They suggested that, regardless of mode of delivery, course quality could be improved through a faculty performance evaluation system that paid more attention to excellence in teaching.

\section{Promote Excellence in Teaching}

One of the issues that emerged during interviews with faculty was that, at that university, excellence in teaching was not as emphasized and rewarded as the ability to attract research grants, conduct research, and publish in refereed academic journals. Given that this study was conducted in a research intensive university, it was not surprising that research was given more prominence than teaching. Majority of the faculty participants felt that their careers "would be made in research and grants." One member of faculty commenting on the low emphasis given to teaching compared to research, said: "teaching is just not a priority, and so it is not discussed much. It's not emphasized on the annual 
reviews. It's not emphasized when we get together as faculty, and discuss things. It's just not a priority." Another participant discussing the lack of emphasis on teaching compared to research explained:

...there are incentives to publish research papers. It goes directly to how much money you are going to get in your salary raise. Teaching is included, but is not valued as much. If you want to get another job somewhere else where you get a big [salary] raise, it's going to be your research that matter... Grants are greatly incentivized here. If you get a grant, you get money directly back into your salary. You buy yourself out of courses [teaching]....So, what incentive is there for great teaching? There's none....So, yeah, there's just no structure to exemplify and uphold great teaching, whereas there is, in terms of research and grants...[F5]

Faculty participants indicated that low emphasis on excellence in teaching was a major factor that determined whether or not faculty took part in institutional initiatives such as seminars or training sessions aimed at improving design and delivery of courses. One faculty participant explained:

When faculty are presented with an option of going to a free seminar which they are going to get nothing except maybe some ideas to teach better, or spend their time doing more research or writing, they are going to spend their time doing research or writing unless you offer incentives for that activity of going and getting trained to be better teachers online... [F2]

In general, faculty and administrator participants felt that in order to further improve course quality, there was need to raise the stature of teaching, consistently evaluate faculty performance in teaching, and reward those who excel. As one administrator explained, a heightened emphasis on teaching "certainly has the potential to enhance the quality of courses."

An administrator participant disclosed that the university planned to review how faculty were evaluated in their teaching. The first phase in that process involved redesign of the student course evaluation forms and was complete at the time of this study. The second phase was planned to be the formation of a faculty panel consisting of "curator professors, curator teaching professors, and faculty honored for excellence in teaching and research" to outline how the university should evaluate the contribution of faculty in teaching and learning. The administrator explained that the committee would be expected to define that process, identify the metrics that should be included in such an evaluation, and explain how the process would relate to the evaluation and coaching undertaken by heads of departments. The administrator further explained that these measures were undertaken partly as a result of a prior study that showed that "faculty at the university wanted the stature of teaching increased." In general, majority of faculty and administrators favored a balanced approach involving use of several metrics, in assessing the effectiveness of faculty and quality of courses.

\section{Quality Improvement Culture}

Generally, participants maintained that course and program quality could be sustained by having an institutional culture that continually seeks improvement. In particular, participants emphasized the need to continually strengthen faculty support mechanisms and the processes of acquiring and implementing technologies for teaching and learning. They stressed the importance of strategically using empirical data in making improvement decisions, and deliberately encouraging stakeholders to develop and maintain a culture of excellence. 
Enhance Faculty Support

Faculty and administrator participants expressed the need for further enhancement of faculty support, especially with regard to providing faculty with opportunities to improve their skills in teaching online. Faculty also stressed on the need to be provided with ondemand support and opportunities to share information pertaining to online teaching among themselves.

\section{Provide faculty with opportunities to improve online pedagogy}

A faculty participant suggested that the university should consider providing training in online teaching pedagogy for interested faculty and all graduate teaching assistants prior to their teaching online. The participant argued that since online teaching is fairly new, many members of faculty have little or no experience in teaching online courses and so might teach them the way they best know how - like on-campus courses. Noting that learning management systems do not necessarily have all the features that an online instructor might want to use in teaching, he also argued that faculty need to be provided with support in learning new technologies that could be useful in delivery of instruction as well as in keeping current with these technologies.

Some administrator participants also discussed the university's future plan to offer more faculty support in design and delivery of courses by establishing a Center for Teaching Excellence and a Summer Institute. The Center for Teaching Excellence is to provide interested faculty with the opportunity to improve their teaching by imparting skills in planning, design, and delivery of technology enhanced courses. The Summer Institute would give faculty ample time to develop online courses and programs during the institution's summer break. Faculty across departments and disciplines participating in the Summer Institute would be paid to work with expert course designers to develop online courses and programs. This "immersion experience", it was hoped, would provide skills and knowledge in course design as well as "create opportunities for inter-disciplinary collaboration across courses and curriculum."

\section{Provide support on demand to faculty}

An issue that frequently emerged was the feeling by faculty that there was a lot of demand for their time. Faculty participants indicated that normally, their time schedules are not very flexible. They therefore found it difficult to take advantage of institutional support initiatives such as training sessions which were offered on fixed schedule basis. As such, they proposed that pedagogical and technical support be provided at the college level. Noting that some schools and colleges of the university already had such support, one participant expressed:

Instead of everyone going out to a central place for training, I would really support expanding the e-learning specialists program where an e-learning specialist who can work closely with faculty, is provided to each college. I think it is done to some extent, but there is need for closer technical support in terms of learning technologies and how they can enhance effective teaching and learning. Our college does not have one of these $e-$ learning specialists... [F1]

Another participant calling for support on demand explained that:

Anything that's called support is going to take time. So, I think having folks [support] available when faculty have questions is really important. So, if I decide I want to use Tegrity, then is there somebody who could show me how to do that. But my guess is that's the kind of thing that faculty are going to be way more available to do than... 'we've scheduled something from twelve to two [12pm -2pm] on Friday afternoons'... that's harder for folks [F5]. 
Improve on strategies for sharing information among faculty

Majority of faculty participants were aware that the university provided opportunities for faculty and external experts to share their experience and expertise in use of technology in teaching and learning, but they thought that such initiatives needed to be improved. For example, one participant claimed that training sessions were "often set up where someone describes something they do rather than 'here is how you do it' and giving you a take away so that you can actually do it..." Another participant talked of the need to invite renowned national experts on learning technologies on regular basis to interact closely with faculty at college or departmental level, over a reasonable period. She thought that inviting these experts to present in one session during training seminars or conferences organized at the university, might not be effective. Another participant proposed that a portal be developed for show-casing new learning technologies or sharing strategies for teaching and learning with technology, that have worked in the past. She suggested that the portal should also be a repository for material that inform faculty on how to use various technologies in teaching, so that "you [faculty] do not need to always go to a workshop or to have someone to help you." Explaining the value of sharing such information, one participant said that without it "you tend to only use what you know."

\section{Optimize Class Size}

Faculty participants expressed the need for improved communication between administrators and faculty at departmental level, regarding the number of students in a course. They felt that there was need for putting a cap on the maximum number of students per course based on the nature of the course and desired learning outcomes. They felt that having a large online class can negatively impact their teaching and subsequently, course quality. One faculty participant said:

I think course enrolments need to be held down instead of jerking up...instead of getting as many students into each course as they possibly can. There needs to be caps on course size based on what can be effective for that particular course. ....there needs to be caps on course size that are based on learning outcomes, not just money...[F1]

Commenting on online course size, another participant suggested that departments find ways to "keep them small and manageable."

Improve the Process of Acquiring and Using Teaching and Learning Technologies An issue that arose severally during interviews with administrators was the need for the university to improve its process for acquisition and implementation of teaching and learning technologies and other innovations in education. One administrator said:

I would love to see better and clearer mechanisms for technology innovation. I think that is something we don't have a very clear way for faculty members or for anybody to be able to explore new technologies, to look at them from lots of different perspectives and to get them accepted for use at the university....[A5]

The administrator added that before any technologies could officially be accepted for use in teaching and learning at the university, they ought to be screened and cleared on such pertinent issues as security, Family Educational Rights and Privacy Act (FERPA) concerns, licensing issues, and on Americans with Disabilities Act (ADA). She argued that the whole process of clearance, including application for funding for technology acquisition, needed to be made clearer to the university community. Some faculty participants also expressed concern over the existing bureaucracy in those processes at the university.

Another issue that some faculty participants raised was the need to promote use of technology including web-based technologies in courses delivered in all formats, not just in online courses. They argued that to make it easier and seamless for students and faculty to migrate from face-to-face modes of instruction to VLEs, the university should consider 
intensifying its campaign to promote relevant use of web-based technologies such as Web 2.0 tools and applications in courses that are online, face-to-face, or those delivered in both formats (hybrid). They opined that motivating faculty who teach only face-to-face courses to adopt and implement web-technologies, for certain course tasks, would enable them and their students to gradually become more comfortable with use of technology in teaching and learning. One participant who also taught face-to-face courses explained how she ensured that she used some web-applications in each of her on-campus courses. She said:

I think that online and on-campus courses should not be made to look like they are too separate. There ought to be a flow... So, for instance, with $m y$ campus courses, we still have a course site. We still use VoiceThread. You know, during a snow day, we still meet, we just meet online... [F3]

However, to ensure ease of access, she stated that such technologies should be compatible with a wide variety of devices including portable ones, such as smart phones and tablets that gave students the flexibility to access course content from multiple locations.

\section{Make Strategic Use of Data}

This strategy was uniquely advanced by administrator participants. They felt that there was need to enhance the use of data to support decision making, especially pertaining to improving teaching and learning. In particular, they highlighted the need for the university to use results from studies on improving teaching and learning i.e. 'scholarship of teaching'; to utilize learning analytics; and to encourage faculty to optimally utilize existing course quality improvement mechanisms such as student course evaluations and course quality standards.

\section{Encourage 'scholarship of teaching'}

Two administrator participants mentioned that the university planned to intensify its efforts to encourage faculty to conduct empirical research related to improving teaching and learning, and to publish their results. They said that doing so would provide administrators with verifiable data that they could use to make decisions in such areas as faculty support and acquisition of teaching and learning technologies. Administrator participants indicated that studies on how the use of specific computer tools and applications might have impacted learning outcomes, effects of course redesign, or other issues encountered in use of learning technologies at the university, might be useful in guiding them to make decisions on related matters. One administrator explained that one of the challenges that the university faced was lack of "appropriate ways to intentionally assess accurately, how use of educational technologies was impacting teaching and learning". He gave an example of an application called Tegrity that the university had acquired to allow faculty to electronically capture lectures and provide them online, saying that he was unaware of how students utilized that application and the impact it had on learning outcomes.

\section{Incorporate the use of learning analytics}

Two administrator participants expressed the need to rely more on the use of data to support strategic decision making in relation to technology utilization in teaching and learning. They opined that having adequate information on such elements as the number of online courses on offer every semester, the types of computer tools and applications used in these courses and their usage patterns, could be useful in identifying issues arising from their use. Reports on usage patterns could provide symptoms of potential problems in learner retention and persistence, or even to identify difficulties in use of these technologies. Analysis of these data could be useful to university administrators in making decisions and optimizing service delivery in such areas as faculty support and student support. For example, the university might opt to improve support on technologies that faculty and students have difficulties using or to withdraw support on technologies that are no longer optimally utilized. One administrator revealed that the university was in the process of implementing a tool called 'Starfish' to provide on-demand learning analytics. Nonetheless, majority of the administrator participants were of the opinion that existing 
faculty support initiatives and course quality improvement mechanisms were not optimally utilized. One participant said:

I would like to see more widespread culture of quality assessment in general... that people are interested in looking at online courses from all pieces of information such as student course assessment, Quality Matters Standards, research data... there are lots of pieces of data out there. We would love to see more discussion of that and more thoughtful application of those in [course] quality assessment across the university. [A5]

She further discussed the need for discussion and encouragement at the departmental level for faculty and all concerned to better utilize the available course quality assessment and enhancement mechanisms. She emphasized that using several of the available assessment techniques gives a more wholesome picture of course quality.

\section{Develop and Nurture a Culture of Continual Improvement}

Participants generally felt that the institution should: 1) initiate and maintain an agenda of searching for and implementing course quality improvement opportunities; and 2) identify the things that work well that it should continue to do, those that don't work well that it should stop doing, and those that would really work that it is not doing at all. Stakeholders such as faculty and administrators should then make every effort to find the best, most effective way to improve on a continual basis, at the course, program, and the institution levels. Faculty should also be encouraged to maintain a culture of continuous professional growth and development.

Administrator participants expressed the need for regular assessment to ensure that the university was using "appropriate technologies in the best way possible to support student learning", and engaging in a "continuous process of improving, updating, and enhancing." One administrator expressed the need for the university to consider the following pertinent issues:

What are the things that work really, really well that we [university] should continue to do? What are the things that don't work well that we should stop doing? What are the things that would really work that we are not doing at all? ...the answers to those questions differ from course to course and from instructor to instructor. As a campus, we've got to find the best, most effective way for us to ask and answer those questions on a continual basis... [A2]

Another administrator said that on matters pertaining to quality improvement, the university leaders ought to "work at it all the time" stating that they could never say "we are done", especially because technology keeps on changing.

Administrators were also in agreement that maintaining a culture of continual improvement requires determination and the will to find means to overcome challenges. They mentioned three main challenges that the university faced in attempts to improve course and program quality. These were:

$>$ Limited resources - administrators expressed concern that budget cuts in previous years and the likelihood that the trend of reduction in available funds was expected to continue, might have negative impact on some university plans to improve course quality.

$>$ Difficulties in striking a balance between academic freedom of faculty on the one hand, and the need to optimally utilize available mechanisms of course quality improvement and also meet quality expectations of external stakeholders - such as the community - on the other hand.

$>$ Faculty resistance - in addition to faculty desire to exercise their academic freedom, some administrators claimed that there were some faculty who do not 
accept that they need guidance to effectively perform their teaching roles, and that even providing incentives to them does not necessarily guarantee that they will participate in course quality improvement initiatives.

\section{SUMMARY OF PERCEIVED CHALLENGES AND RECOMMENDED SOLUTIONS}

Table 3 below summarizes the emergent challenges and the main solutions suggested by participants.

Table 3. Perceived Faculty Challenges in Design and Delivery of Quality Online Courses and Proposed Solutions

\section{Challenge}

Limited opportunities for understanding learners and their learning needs

\section{Proposed Solutions}

- Encourage faculty to provide for and encourage occasional audiovisual synchronous meetings (virtual office hours) with individual students.

- Utilize collaborative group work where the nature and structure of the course allows. Doing this enables students to learn from each other rather than relying heavily on the course instructor.

- Encourage faculty to use computer tools and applications that support virtual communication and interaction, and support them in acquiring, adopting, and utilizing those technologies.

Impact of large online class sizes on course quality

- Encourage open communication at departmental and higher levels in determining the optimum number of learners in each course that retains the economic viability of the course and does not hinder achievement of desired learning outcomes.

Need for faculty to have technical and pedagogical skills relevant for teaching online

- Provide paid 'course free hours' to faculty who are tasked to design a new course or to redesign a course.

- Provide training opportunities that are customized to the needs of faculty.

- Provide adequate technical and pedagogical support on demand.

- Encourage faculty to proactively seek feedback from students about 'what works and what does not'.

Perceptions that teaching of online courses is time intensive

- Provide adequate technical support and pedagogical support on demand

- Ensure class sizes are at a level that allows effective instruction i.e. ensure that institutional economic needs do not override or sacrifice course quality through enrollments that overload course instructors

- utilize collaborative group work where the nature and structure of the course allows

- provide opportunities for faculty who teach online courses to share information and experiences related to improving teaching and learning on VLEs

Course management systems have limitations that impact the quality of online course delivery

- provide adequate support to faculty in selecting and utilizing computer tools and applications that fit their preferred instructional strategies and overall teaching philosophy

- Provide, as much as possible, the latest versions of LMS used at the institution.

- Encourage and support faculty to use a variety of computer tools that support achievement of desired learning outcomes.
Keeping updated with rapidly changing learning

technologies
- Facilitate faculty with support that promotes their efforts to explore, experiment with and learn to use newer, innovative technologies. Such support could be technical, financial, or provision of relevant information sources. 
Lack of adequate institutional processes and funding to support acquisition and maintenance of learning technologies
- Provide clear guidelines on how faculty can request for computer tools or applications for teaching and learning

- Institution should consider negotiating for site licenses and student prices with vendors of computer tools or applications that support teaching and learning.

- Provide funding for acquisition of computer tools or applications that faculty might want to use to augment - or to add to technologies already acquired and supported by the institution.

- Consider assessing the effectiveness of technologies already acquired, for example, using learning analytics, to ensure costefficiency.

Difficulties in observing and assessing practical application of knowledge gained in VLEs

- Where distance is an issue, initiate agreements with qualified third parties who will assess application of practical knowledge, on behalf of the instructor and the institution offering the course.

- Where technology infrastructure and nature of the course allows, use appropriate online applications that facilitate real-time observation of a student.

Feelings of isolation and limited opportunities for - Institution to consider providing means by which faculty teaching online courses can share information and experiences related to professional development, and actively encourage them to participate in such initiatives.

\section{DISCUSSION AND CONCLUSION}

Three broad categories of the major challenges encountered by faculty in the design and deliver of online courses emerged in this study. These related to: 1) proximity to learners; 2) teaching load; and, 3) faculty support. A general inference that one could make from this finding is that these challenges could have some relationship with perceptions of course quality, as explained here below. Difficulties in getting to adequately understand learner needs in a virtual environment impacts faculty perceptions of their ability to design quality courses and quality teaching and learning processes. For example, inability to sufficiently understand learner needs might lead to instruction design that does not adequately address learners learning needs, while difficulties in assessing practical application of knowledge may impact faculty ability to assess attainment of course objectives.

Faculty suggested that teaching overload can impact processes that have a bearing on online course quality. For example, they indicated that large class size is a challenge because it negatively impacts elements of course processes such as creation of a cohesive community of learners and ability to provide adequate faculty feedback to all learners. Faculty perceptions of overload might also indicate administrative lack of adequate dialogue with faculty on optimal class size and instead opting for better income that larger classes generate. Similarly, the perception by faculty that an online course requires more time than does a similar face-to-face course might be indicative of lack of appropriate faculty support, which could impede the ability of faculty to implement quality course processes. Even though administrators indicated their awareness of the importance of faculty support in providing quality online courses, faculty and administrators appeared to have differing concepts of what is effective faculty support. A mismatch between the support that faculty need and the support provided by the university may impact their ability to design and deliver courses that facilitate achievement of students' educational goals.

The solutions proposed for alleviating perceived challenges in the design and delivery of quality online courses suggests that creating an institutional mission and culture that recognizes faculty support needs, as well as promoting excellence in teaching and encouraging continuous improvement in elements of course design, course processes, and 
infrastructure to support online courses, could positively impact faculty perceptions of course quality.

Two issues related to course quality spontaneously emerged from this study: 1 ) the relative importance of teaching versus research in assessing faculty performance; and 2) academic freedom of faculty. Both of these issues were found to be related to faculty awareness and willingness to participate in course quality improvement initiatives. Faculty reported not feeling motivated to excel in teaching, since doing so was not given much credit compared to conducting research, in assessing their overall performance. In that regard, some faculty participants indicated that they did not pay much attention to institutional course quality improvement initiatives. Faculty comments that use of course quality standards might not be in line with their teaching philosophy and could impact their academic freedom calls for improved dialogue between academic administrators and faculty. Additionally, administrators need to have clear and effective strategies of communicating to faculty about the various course quality improvement initiatives that they have instituted, and the benefits that faculty gain by participating in them. In assessing faculty performance, the stature of excellence in teaching should be high enough to motivate faculty to engage in and actively utilize course quality improvement initiatives. HEIs should also consider developing and using balanced, multiple-measure faculty performance assessment criteria, that as much as possible takes into consideration the interests of main stakeholders, as pertains to course and program quality.

In conclusion, as demand for online courses continues to grow and technology gradually improves to provide better opportunities for online interaction, HEIs will be under pressure to offer or to continue to offer online courses that meet stakeholders' quality requirements in an effective and efficient manner. It is important for providers of online courses to realize the critical role that adequate faculty support plays in ensuring course quality. In order to develop and maintain effective faculty support strategies and systems, HEIs need to continually assess the challenges that faculty face in design and delivery of courses through VLEs, and to prioritize efforts to remediate them.

\section{BIODATA and CONTACT ADDRESSES of AUTHOR}

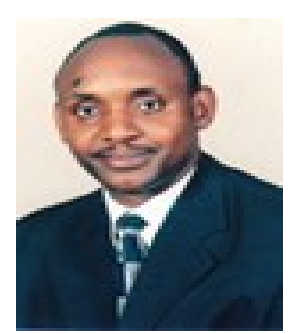

Francis KIBARU is the Head of the Department of Information and Communication Technology at the Commission for University Education, Kenya. Dr. Kibaru gained his Ph.D. in Learning Technologies in December, 2013. His academic interest areas are human-computer interaction, elearning, technology usability, open and distance learning, and electronic performance support systems. He has over than fourteen articles published in refereed journals and proceedings of international academic conferences.

Francis KIBARU

Department of Information and Communication Technology

Commission for University Education

Redhill Rd, off Limuru Rd, Gigiri

PO BOX 5499900200 Nairobi, Kenya

Phone: + 254 (20) 7205250; 0726-445566; 0780-656575

Email: fkibaru@cue.or.ke

\section{REFERENCES}

Allen, I.E. \& Seaman, J. (2017). Digital learning compass: Distance education enrolment report 2017.

Baran, E. \& Correia, A. P. (2014). A professional development framework for online teaching. Techtrends, 58, 96-102. doi:10.1007/s11528-014-0791-0. 
Berge, Z.L. (1995). Facilitating computer conferencing: Recommendations from the field. Educational Technology. 35(1) 22-30.

Bolliger, D. U., \& Wasilik, O. (2009). Factors influencing faculty satisfaction with online teaching and learning in higher education. Distance Education, 30(1), 103-116. doi:10.1080/01587910902845949

Clark, D. B., Tanner-Smith, E. E., \& Killingsworth, S. S. (2016). Digital games, design, and learning: A systematic review and meta-analysis. Review of Educational Research, 86(1), 79-122.

Creswell, J.W. (2007). Research Design: Choosing among five approaches. Thousand Oaks, CA: Sage.

Dabbagh, N., \& Bannan-Ritland, B. (2005). Online learning: Concepts, strategies, and applications. Upper Saddle River, New Jersey: Pearson Prentice Hall.

Daniel, J. \& Uvalic'-Trumbic', S. (2013) A guide to quality in online learning. Retrieved October 10, 2017 from http://www.chea.org/userfiles/uploads/A\%20Guide\%20to\%20Quality\%20in\% 200nline\%20Learning.pdf

Friedman, J. (2017). Five Online Education Trends to Watch in 2017. Retrieved October 20, 2017 from https://www.usnews.com/higher-education/onlineeducation/articles/2017-01-05/5-online-education-trends-to-expect-in-2017

Garza, R. L. (2009). Online education and organizational change. Community College Review, 37(1), 81-101.

Garza, R. L. (2010). Approaching common ground: Defining quality in online education. New Directions for Community Colleges, 150, 89-94.

Gaytan, J. (2015). Comparing faculty and student perceptions regarding factors that affect student retention in online education. American Journal of Distance Education, 29(1), 56-66.

Hunt, D., Davis, K., Richardson, D., Hammock, G., Akins, M., \& Russ, L. (2014). It is (more) about the students: Faculty motivations and concerns regarding teaching online. Online Journal of Distance Learning Administration, 17(2).

Jung, I. S. (2008). Quality assurance and continuous quality improvement in distance education. In T. Evans. Haughey, \& D. Murphy (Eds.), International handbook of distance education (pp. 609-624). London: Emerald Group Publishing Limited.

Jung, I. S. (2010). The dimensions of e-learning quality: from the learner's perspective. Education Technology Research and Development, DOI:10.1007/s11423-0109171-4.

Jung, I. S., Wong, T. M., Chen L., Baigaltugs, S., \& Belawati, T. (2011). Quality assurance in Asian distance education: Diverse approaches and common culture. International Review of Research in Open and Distance Learning, 12(6), 63-83.

Kim, K.J., \& Bonk, C. J. (2006). The future of online teaching and learning in higher education: The survey says... Educause Quarterly, 29(4), 22-30

Ko, S. \& Rossen, S. (2010). Teaching online: A practical guide. New York: Routledge

Kolomitro, K., \& MacKenzie, L. W. (2017). Using Assessment to Promote Deep and Active Learning in an Online Anatomy Course. The FASEB Journal, 31(1 Supplement), 584-2.

Lieblein, E. (2000). Critical factors for successful delivery of online programs. Internet and Higher Education, 3(3), 161-174.

Lincoln, Y., \& Guba, E. (1985). Naturalistic inquiry. New York: Sage. 
Liu, X., Bonk, C. J., Magjuka, R. J., Lee, S., Su, B. (2005). Exploring four dimensions of online instructor roles: A program level case study. Journal of Asynchronous Learning Networks 9 (4), 29-48.

Martin, F., \& Ndoye, A. (2016). Using learning analytics to assess student learning in online courses. Journal of University Teaching \& Learning Practice, 13(3), 1-20.

Martin, F. \& Parker, M.A. (2014). Use of Synchronous Virtual Classrooms: Why, Who and How? MERLOT Journal of Online Learning and Teaching, 10(2), 192-210.

Martin, F., Polly, D., Jokiaho, A., \& May, B. (2017). Global standards for enhancing quality in online learning. The Quarterly Review of Distance Education, 18(2), 1-10.

Merchant, Z., Goetz, E. T., Cifuentes, L., Keeney-Kennicutt, W., \& Davis, T. J. (2014). Effectiveness of virtual reality-based instruction on students' learning outcomes in K-12 and higher education: A meta-analysis. Computers \& Education, 70, 29-40.

Miles, M. B. and Huberman, A. M. (1994). Qualitative data analysis: An expanded sourcebook, 2nd Ed. Thousand Oaks: Sage.

Orr, R., Williams, M. R., \& Pennington, K. (2009). Institutional efforts to support faculty in online teaching. Innovative Higher Education, 34(4), 257.

Sellani, R. J., \& Harrington, W. (2002). Addressing administrator/faculty conflict in an academic online environment. The Internet and Higher Education, 5(2), 131-145.

Shelton, K., (2011). A review of paradigms for evaluating the quality of online education programs. Online Journal of Distance learning Administration, 4(1).

Smith, D.F. (2014). 10 Online Learning Trends to Watch in 2015. Retrieved November 4, 2017 from http://www.edtechmagazine.com/higher/article/2014/12/10-onlinelearning-trends-watch-2015-infographic-0

Stella, A. \& Gnanam, A. (2004). Quality assurance in distance education: the challenges to be addressed. Higher Education, 47,143-160

Sun, P., Tsai, R. J., Finger, G., Chen, Y., \& Yeh, D. (2008). What drives a successful elearning? An empirical investigation of the critical factors influencing learner satisfaction. Computers and Education, 50(4), 1103-1586.

Taylor, A., \& McQuiggan, C. (2008). Faculty development programming: If we build it, will they come? Educause Quarterly, 31(3), 28-37

Twigg, C. (2001). Innovations in online learning: Moving beyond no significant difference. New York: Center for Academic Transformation. Retrieved on September 20, 2015, from http://www.thencat.org/Monographs/Mono4.pdf

Weaver, D., Robbie, D., \& Borland, R. (2008). The practitioner's model: Designing a professional development program for online teaching. International Journal on ELearning, 7(4), 759-774.

Wu, J. P., Tsai, R. J., Chen, C. C., \& Wu, Y. C. (2006). An integrative model to predict the continuance use of electronic learning systems: hints for teaching. International Journal on E-Learning, 5(2), 287-302 